\title{
Pharmacokinetics and Pharmacodynamics of
} YYD60I, a Dual Delayed-Release Formulation of Esomeprazole, Following Single and Multiple Doses in Healthy Adult Volunteers Under Fasting and Fed Conditions

\author{
Hae Won Lee $\mathbb{D}^{1,2}$, Woo Youl Kang $\mathbb{D}^{1,2}$, Wookjae Jung $\mathbb{D}^{1,2}$, Mi-Ri Gwon ${ }^{1,2}$, Kyunghee Cho ${ }^{3}$, Young-Ran Yoon $\mathbb{D}^{1,2}$, \\ Sook Jin Seong ${ }^{1,2}$ \\ 'Department of Molecular Medicine, School of Medicine, Kyungpook National University, Daegu, 41944, Republic of Korea; ${ }^{2}$ Department of Clinical \\ Pharmacology, Kyungpook National University Hospital, Daegu, 41944, Republic of Korea; ${ }^{3}$ Analytical Research Division, Biocore Co. Ltd., Seoul, \\ 085 I I, Republic of Korea \\ Correspondence: Young-Ran Yoon, Department of Molecular Medicine, School of Medicine, Kyungpook National University, I 30 Dongdeok-Ro, Jung-gu, Daegu, \\ 41944, Republic of Korea, Tel +82 53-420-4950, Fax +82 53-420-5218, Email yry@knu.ac.kr; Sook Jin Seong, Department of Clinical Pharmacology, School of \\ Medicine, Kyungpook National University, I 30 Dongduk-Ro, Jung-gu, Daegu, 41944, Republic of Korea, Tel +82 53-200-635I, Fax +82 53-420-52I8, \\ Email wintersj@knu.ac.kr
}

Background: YYD601 was developed as a novel dual delayed release (DDR) formulation of esomeprazole to prolong the plasma esomeprazole concentration and extend the duration of acid suppression.

Purpose: The pharmacokinetic (PK) and pharmacodynamics (PD) characteristics of YYD601 after single and multiple oral administrations were investigated in healthy Korean adults under fasting and fed conditions, and compared with the original esomeprazole capsule. Methods: In the single-center, randomized, open-label, parallel-design, two-period study, thirty two volunteers were enrolled into four dosing groups, including esomeprazole 40-mg (group A), YYD60130-mg (group B), YYD601 40-mg (group C), and YYD601 60-mg (group D) once daily for 5 days. Blood samples were collected for PK analysis, before and up to $24 \mathrm{~h}$ after dosing. For PD characteristics of YYD601, the percentages of time with intragastric $\mathrm{pH}>4$ over a 24-h period and during night-time following multiple oral administrations were evaluated. Results: A total of 27 subjects completed the study. YYD601 showed a dual-peak PK profile under fasting condition, with delayed $\mathrm{T}_{\text {max, }}$ compared with conventional formulation. There were no significant differences in the AUC values adjusted for dose between the three YYD601 dosage groups and the conventional esomeprazole $40 \mathrm{mg}$. The esomeprazole AUC following single and multiple administration decreased with food intake by approximately 33\%. YYD601 showed a linear pharmacokinetic profile in the dose range studied. There was no statistically significant difference in increase in mean percentage of time with intragastric $\mathrm{pH}>4$ for 24-hour and during night-time between the three different doses of YYD601 and the conventional formulation. The treatments were well-tolerated during the study and no serious adverse events were observed.

Conclusion: YYD601 $30 \mathrm{mg}$ has a comparable effect on gastric acid inhibition as conventional esomeprazole $40 \mathrm{mg}$ following once daily oral administration. Single and multiple oral dosing of YYD601 up to $60 \mathrm{mg}$ were safe and well-tolerated throughout the study. Clinical Trial Registry: http://clinicaltrials.gov, NCT03558477 (date of registration: June 15, 2018; study period: between October 2017 and February 2018).

Keywords: esomeprazole, dual delayed release, pharmacokinetics, pharmacodynamics

\section{Introduction}

Gastroesophageal reflux disease (GERD) is one of the most common diseases of the upper gastrointestinal tract, with a prevalence of a few to more than $30 \% .{ }^{1}$ The reflux of stomach contents causes troublesome symptoms, including 
heartburn and regurgitation, which leads to serious complications, such as stricture, Barrett's esophagus, and esophageal adenocarcinoma, if left untreated. ${ }^{2}$

Gastric acid is of key importance to the pathogenic process of esophageal mucosal injury in patients with GERD. ${ }^{2,3}$ Evidence shows a correlation between an intragastric $\mathrm{pH}$ of less than 4.0 and the degree of mucosal injury. ${ }^{4}$ Accordingly, the vital objective in the effective management of GERD focuses on maintaining intragastric $\mathrm{pH}$ above the threshold of four. ${ }^{5}$ Proton pump inhibitors (PPIs) have been the treatment of choice in GERD and other upper gastrointestinal tract acid-related conditions because of greater efficacy and lack of pharmacologic tolerance compared to histamine-2 receptor antagonists. ${ }^{6}$ PPIs reduce the secretion of hydrochloric acid by gastric parietal cells by blocking the activity of the gastric $\mathrm{H}^{+} / \mathrm{K}^{+}$-ATPase enzyme (the proton pump). ${ }^{7}$ However, most PPIs have relatively short plasma half-lives of $1-2 \mathrm{~h}$ with limited mean residence time in the systemic circulation, and not all proton pumps are active simultaneously. ${ }^{7}$ Therefore, gastric acid secretion is not completely controlled with a once-daily oral dose of conventional PPIs. Although twice-daily PPI therapy would provide more prolonged acid suppression, nocturnal acid breakthrough (NAB), defined as intragastric $\mathrm{pH}$ less than four for at least 60 consecutive minutes in the overnight period, was observed in more than $70 \%$ of patients on a twice-daily PPI therapy. ${ }^{8}$ As a twice-daily dose reduces adherence to treatment regimens, a once-daily dose with a better pharmacokinetic/pharmacodynamic profile that would more reliably control the night-time gastric acid secretion is the preferred alternative for administration. ${ }^{9}$

The intragastric $\mathrm{pH}$ elevation effect of esomeprazole, the S-isomer of omeprazole, administered once daily at a dose of $40 \mathrm{mg}$ in healthy volunteers and patients with symptoms of GERD, was superior to that of omeprazole, lansoprazole, rabeprazole, and pantoprazole in several randomized, crossover trials. ${ }^{10-12}$ YYD601 is a delayed-release (DR) formulation of esomeprazole developed by the YooYoung Pharm. Co. Ltd. (Jincheon, Chungcheongbuk-do, Republic of Korea), which employs a similar dual delayed-release (DDR) delivery system to that of the dexlansoprazole MR (Dexilant ${ }^{\mathrm{TM}}$, TAK-390MR, Takeda Global Research \& Development Center, Inc., Deerfield, IL, USA). ${ }^{9}$ The esomeprazole DDR formulations contain a mixture of two granules, with half of the drug released first (DR) and the remaining $50 \%$ of the drug later (DR), resulting in the addition of the second peak to the single peak $\left(\mathrm{C}_{\max }\right)$ of the conventional esomeprazole. It was designed to improve medication compliance and better control NAB by prolonging the duration of drug exposure and subsequently extending acid suppression with a single daily dose. ${ }^{13}$

After oral administration, peak plasma concentration of esomeprazole was reached between 1 to 3.5 hours after dosing, and it is extensively metabolized to its major inactive hydroxyl and desmethyl metabolites mainly by cytochrome P450 (CYP) 2C19. ${ }^{10,14,15}$ Esomeprazole is highly bound to plasma proteins (97\%). ${ }^{14}$ The mean elimination half-life was about 1 to $1.5 \mathrm{~h}$. Most $(80 \%)$ of the dose was excreted as inactive metabolites in the urine, and to a lesser extent in feces. ${ }^{10,14}$

The administration of most PPIs under fed conditions resulted in decreased bioavailability relative to that under fasting conditions. For esomeprazole DR capsule, food intake decreased $\mathrm{C}_{\max }$ by $74-78 \%$ and AUC by $43-53 \%$, with delayed $\mathrm{T}_{\max }$ by $2.5-3 \mathrm{~h} .{ }^{14,16,17}$ The presence of food reduced the AUC and $\mathrm{C}_{\max }$ of lansoprazole DR capsules (both by $50 \%$ ), and delayed $\mathrm{T}_{\max }$ (from 1.8 to $3.3 \mathrm{~h}$ ). ${ }^{18}$ Coadministration of orally disintegrating tablets of dexlansoprazole and food led to significantly delayed $\mathrm{T}_{\max }$ (from 4 to $6 \mathrm{~h}$ ) and decreased $\mathrm{C}_{\max }$ by $38 \% .{ }^{16}$ According to the US Food and Drug Administration guidance, for all modified-release drug products, the food effects on formulation bioavailability are complicated to predict without conducting a fed BE study. ${ }^{19}$ Accordingly, the pharmacokinetic parameters of YYD601 were compared between fasting and fed conditions in this study.

This study was conducted to investigate the pharmacokinetic and pharmacodynamic characteristics of esomeprazole DR, YYD601, after single and multiple oral administrations in healthy Korean adults under fasting and fed conditions.

\section{Methods}

\section{Study Design and Subjects}

This was a single-center, randomized, open-label, parallel-design, two-period, single- and multiple-dose pharmacokinetic/pharmacodynamic study performed on healthy volunteers under fasting and fed conditions, between October 2017 and February 2018. 
The protocol was reviewed and approved by the Institutional Review Board of Kyungpook National University Hospital (KNUH, Daegu, Republic of Korea) (Approval No. 2017-09-002). The study was conducted following the principles outlined in the Declaration of Helsinki and the Good Clinical Practice guidelines. The subjects were provided with written informed consent to participate in this study before initiating the study.

This study enrolled healthy volunteers aged $>18$ years, who weighed $\geq 50 \mathrm{~kg}$ and were within $\pm 20 \%$ of ideal body weight. The subjects were screened for eligibility, determined based on medical history, physical examination, vital signs, clinical laboratory tests (blood hematology, urinalysis, and serum chemistry), and a 12-lead electrocardiogram. Exclusion criteria were a history of or current disease (hepatobiliary, renal, cardiovascular, endocrine, respiratory, immune, gastrointestinal, hematologic, central nervous system, psychiatric, and musculoskeletal) that could affect the absorption, distribution, metabolism, and excretion of the study drug; a history of hypersensitivity to any drug, including esomeprazole or benzimidazole; and presence of active liver disease or serum aspartate aminotransferase, alanine aminotransferase, or total bilirubin levels $>1.5$ times the upper limit of normal. Additional exclusion criteria included a positive test result for ${ }^{13} \mathrm{C}$ urea breath test; the presence of peptic ulcer, esophageal disease (GERD, Barrett's esophagus, erosive esophagitis), or Zollinger-Ellison syndrome within 3 months of the first administration of the study drug; subjects who could not apply $\mathrm{pH}$ recording system to evaluate 24-h intragastric acidity.

The investigational esomeprazole DR (30-mg, 40-mg, and 60-mg YYD601) were manufactured by the YooYoung Pharm. Co. Ltd. (Jincheon, Chungcheongbuk-do, Republic of Korea), and the active comparator was the 40-mg esomeprazole (Nexium ${ }^{\circledR}$, AstraZeneca Korea, Seoul, Republic of Korea).

Thirty eligible volunteers were randomly assigned to one of four groups (A, B, C, and D), with six subjects in group A, and eight subjects each in groups B, C, and D. In Period I, each subject received 40-mg esomeprazole (group A), 30-mg YYD601 (group B), 40-mg YYD601 (group C), or 60-mg YYD601 (group D) orally once daily for 5 consecutive days in fasting state. There was a washout period of 7 days before the volunteers were switched to Period II that the same doses were administered for 5 days in a fed state. The study design is illustrated in Figure 1. The subjects were hospitalized to the clinical trial center beginning on day -2 and ending on day 6. On day -1 , subjects underwent 24-h intragastric $\mathrm{pH}$ monitoring at baseline. On day 1 , after fasting for $10 \mathrm{~h}$, the study medication was administered with $150-\mathrm{mL}$ water, and the subjects were sampled for pharmacokinetic analysis. Subsequently, the subjects proceeded to multiple dosing (from day 2 to day 5) under fasting conditions as scheduled. On day 5, the subjects received $\mathrm{pH}$ catheter placement again for 24-h intragastric $\mathrm{pH}$ monitoring, and the blood samples were collected for pharmacokinetic analysis after the last dose. The

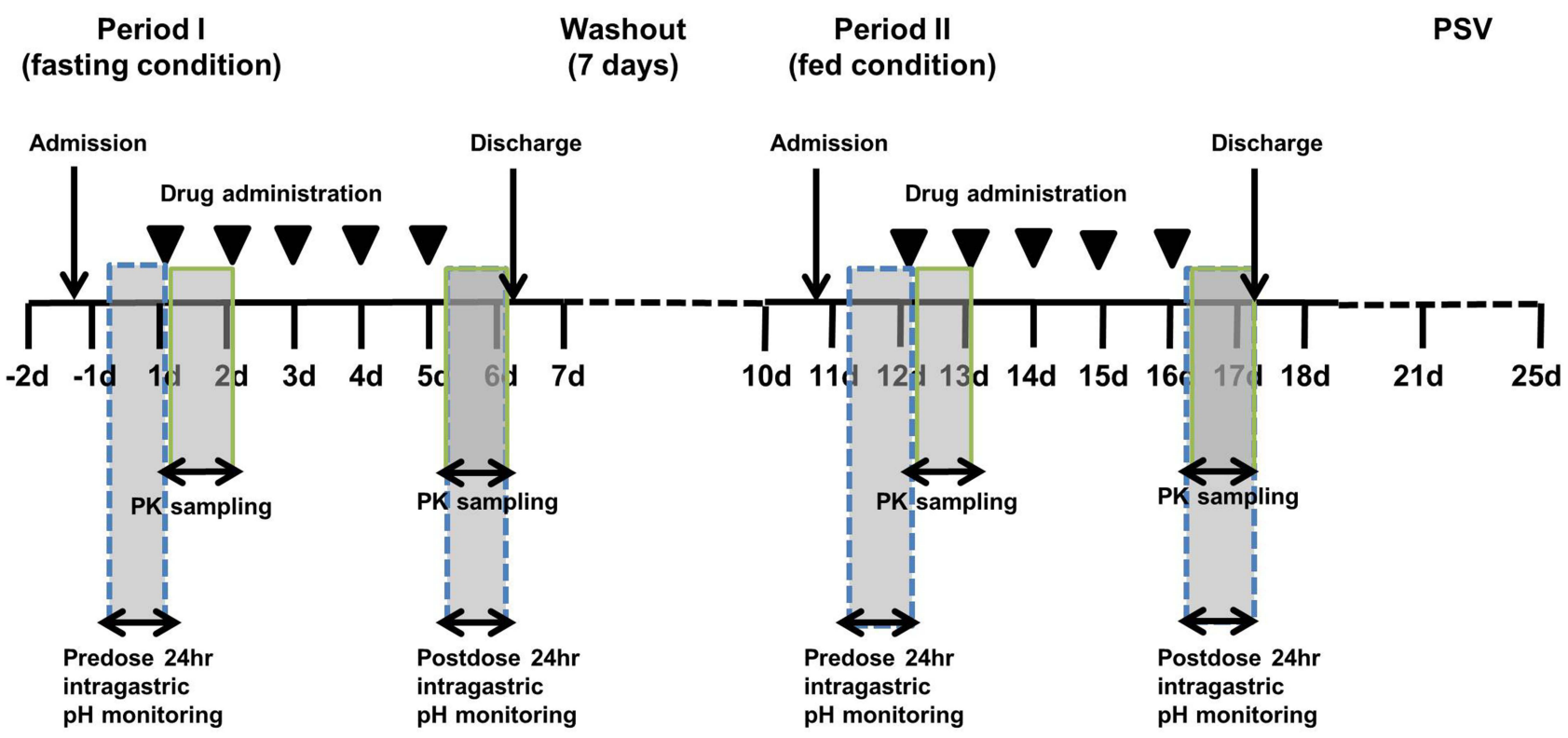

Figure I Study design. In period I, the subjects were administered the study drugs after overnight fasting for 5 days. After a 7-day washout, subjects were administered the same study drugs following a high-fat meal for 5 days. 
subjects remained at the study center until the completion of the final study procedure on day 6 and were discharged from the study center during washout periods. For Period II, the subjects returned to the study center on day 10. Period II was similar to Period I, except that the study medications were administered following a high-fat breakfast (900 kcal; fat > $35 \%$ ). The subjects started the meal $30 \mathrm{~min}$ before the dose and finished in $20 \mathrm{~min}$.

\section{Blood Sampling and Bioanalytical Methods}

A series of venous blood samples ( $6 \mathrm{~mL}$ each) were collected in tubes containing EDTA-K2 at 0 (predose), 1, 1.5, 2, 2.5, $3,3.5,4,4.5,4.75,5,5.25,5.5,6,8,12$, and $24 \mathrm{~h}$ postdose on days 1 (first dose, fasted), 5 (last dose, fasted), 12 (first dose, fed), and 16 (last dose, fed). Within $30 \mathrm{~min}$, the samples were centrifuged at $4^{\circ} \mathrm{C}, 3000 \mathrm{rpm}$ for 10 minutes. The plasma was separated and transferred to three separate amber polypropylene tubes $(1 \mathrm{~mL} /$ tube $)$ and kept frozen at $-70^{\circ} \mathrm{C}$ or lower prior to the analysis. The blood samples were light-proof during the sample preparation procedure.

According to a validated high-performance liquid chromatography method, coupled with triple quadrupole mass spectrometer (API 4000, AB SCIEX, USA), equipped with electrospray ionization in positive ion mode, the plasma concentrations of esomeprazole were determined at an analytical laboratory (BioCore Co., Ltd., Seoul, Republic of Korea). ${ }^{20-22}$ Multiple reaction monitoring transitions of mass-to-charge ratios $346.3 \rightarrow 198.3$ and $349.3 \rightarrow 198.3$ were used for esomeprazole and the internal standard (IS, esomeprazole- $\mathrm{d}_{3}$ ), respectively. The analytes were separated on a C18 column $(50 \mathrm{~mm} \times 2.1 \mathrm{~mm}$ i.d.; $3.5 \mu \mathrm{m}$ particle size; Waters Corporation $)$ at a flow rate of $0.2 \mathrm{~mL} / \mathrm{min}$. The mobile phase consisted of a 60: $40(\mathrm{v} / \mathrm{v})$ mixture of 5-mM ammonium hydroxide and acetonitrile, adjusting to $\mathrm{pH} 8.0$ with formic acid.

Frozen plasma was thawed at room temperature and vortexed for 10 seconds. A 100- $\mu \mathrm{L}$ plasma sample in a polypropylene tube was vortex mixed for 1 minute with $300-\mu \mathrm{L}$ of acetonitrile $(0.1 \%$ triethylamine) and $10-\mu \mathrm{L}$ of the IS $(10,000 \mathrm{ng} / \mathrm{mL})$. After centrifugation at $13,000 \mathrm{rpm}$ for 5 minutes, $100-\mu \mathrm{L}$ supernatant in a polypropylene tube was vortex mixed for 2 seconds with $200-\mu \mathrm{L}$ deionized water ( $0.1 \%$ trimethylamine). Then, $3-\mu \mathrm{L}$ supernatant was injected into the LC-MS/MS system for analysis. The lower limit of quantification was $1.9 \mathrm{ng} / \mathrm{mL}$, and the calibration curve was linear over $1.9-3800 \mathrm{ng} / \mathrm{mL}(\mathrm{r} \geq 0.9992)$. The intra- and interassay accuracies ranged between $90.5 \%$ and $106.0 \%$ and between $95.8 \%$ and $100.6 \%$, respectively. The intra- and interassay precision $\%$ coefficient of variation ranged from $0.7 \%$ to $5.6 \%$ and from $1.3 \%$ to $8.0 \%$, respectively.

\section{Pharmacokinetic Evaluations}

We derived the pharmacokinetic parameters for esomeprazole using actual sampling times with a noncompartmental pharmacokinetic analysis provided by WinNonlin Pro 5.3 (Pharsight Corporation, Mountain View, CA, USA) as follows: the maximum plasma concentration $\left(\mathrm{C}_{\max }\right)$, the time to reach $\mathrm{C}_{\max }\left(\mathrm{T}_{\max }\right)$, the area under the plasma concentration-time curve (AUC) to the last measurable time $\left(\mathrm{AUC}_{\text {last }}\right)$, the $\mathrm{AUC}$ to infinity $\left(\mathrm{AUC}_{\mathrm{inf}}\right), \mathrm{C}_{\mathrm{max}}$ during a dosing interval $(\tau)$ at steady state $\left(\mathrm{C}_{\mathrm{max}, \mathrm{ss}}\right)$; the time to reach $\mathrm{C}_{\text {max,ss }}\left(\mathrm{T}_{\mathrm{max}, \mathrm{ss}}\right)$; $\mathrm{AUC}$ after repeated dosing at steady state $\left(\mathrm{AUC}_{\tau, \mathrm{ss}}\right)$, and elimination half-life $\left(\mathrm{t}_{1 / 2}\right)$.

\section{Pharmacodynamic Measurement}

To assess the pharmacodynamic effect, intragastric $\mathrm{pH}$ was monitored every second using an ambulatory $\mathrm{pH}$ recording system (ZepHr ${ }^{\mathrm{TM}}$; Sandhill Scientific Inc., Highlands Ranch, CO, USA), with a disposable dual pH catheter. The intragastric $\mathrm{pH}$ data were recorded continuously for $24 \mathrm{~h}$ at baseline (on day -1 ) before the first administration of the study medications, and for $24 \mathrm{~h}$ after the last dose on day 5 . The $\mathrm{pH}$ data was stored and processed in the software (Zvu ${ }^{\mathbb{B}}$ v. 2.3.2086.1) for later analysis. A 2.1-mm catheter with a monocrystalline antimony electrode was calibrated before each recording using buffers of $\mathrm{pH} 1.07$ and $\mathrm{pH} 7.01$ at room temperature, according to the manufacturer's instructions. The $\mathrm{pH}$ probe was passed transnasally through the esophagus into the stomach. Recording was commenced at $08.00 \mathrm{~h}$ and lasted for $24 \mathrm{~h}$.

One of the primary pharmacodynamic endpoints of this study was the percentage of time with the intragastric $\mathrm{pH}>4$ during the 24-h period calculated from the intragastric $\mathrm{pH}$ data at baseline (days -1 and 11) and after multiple administrations (on days 5 and 16). The percentage of time with intragastric $\mathrm{pH}>4$ during night-time was also assessed. 
The night-time period was defined as the time period between $11 \mathrm{pm}$ and $8 \mathrm{am}$. Another primary pharmacodynamics endpoint was the percent change of serum gastrin level under the fasting conditions calculated from the values at baseline and on days one and five. Another pharmacodynamic parameter calculated in the study was mean $\mathrm{pH}$ during the 24-h period calculated at baseline (on days -1 and 11) and after multiple administrations (on days 5 and 16).

\section{Safety of Subjects}

The safety profiles included subjective symptoms, vital signs (blood pressure, pulse rate, and body temperature), physical examination findings, clinical laboratory tests, and a 12-lead electrocardiogram. AEs occurring on or after administering the first dose in all subjects who received at least one or more doses of 40-mg esomeprazole or YYD60130-60 mg were documented as treatment-emergent adverse events (TEAEs). The laboratory tests were conducted at an accredited laboratory facility (Department of Laboratory Medicine, KNUH, Daegu, Republic of Korea).

\section{Statistical Analyses}

Demographic characteristics were analyzed using analysis of variance model to compare the four treatment groups.

The primary PK parameters, $\mathrm{C}_{\max }$ and AUC, were log-transformed, dose-normalized, and analyzed using the paired $t$-test or Wilcoxon signed-rank test to compare the two treatment groups (YYD601 and esomeprazole $40 \mathrm{mg}$ ). The geometric mean ratios (GMRs) and 90\% confidence intervals (CIs) of log-transformed dose-normalized $\mathrm{C}_{\max }$ and AUC for the two treatment groups (YYD601 group/esomeprazole $40 \mathrm{mg}$ group) were assessed.

To evaluate the food effects, GMRs and $90 \%$ CIs for the ratios between fed and fasted treatments were estimated in each dose group of YYD601. The absence of the food effect was not concluded if the $90 \%$ CI of GMR for the logtransformed $\mathrm{C}_{\max }$ and AUC was not entirely contained within the predetermined range of $0.800-1.250 .{ }^{19}$

The primary pharmacodynamic parameters were the percentage of time with the intragastric $\mathrm{pH}>4$ for 24 -h period and during night-time, and the percent change in the serum gastrin level (between day -1 and days one and five). Baseline values and the values after administration in each treatment group were compared using a paired $t$-test or Wilcoxon signed-rank test. The mean differences between the YYD601 groups and the 40-mg esomeprazole were compared using the $t$-test.

All statistical analyses were conducted using SPSS for Windows software (ver. 18.0; SPSS Korea, Seoul, Korea), and the level of statistical significance was defined as the $p$-value below 0.05 .

\section{Results}

\section{Subjects}

Figure 2 provides an overview of the study design and subject disposition. A total of 51 healthy volunteers were screened for the study: 30 volunteers were enrolled in the study following initial screening and were randomized to 1 of 4 different treatment groups. One subject from group $\mathrm{C}$ withdrew consent before admission for Period $\mathrm{I}$, and another subject from group B withdrew before administration of study medication in Period I, so that other subjects from the waiting list replaced them. One subject from group A, who withdrew from the study before administration of study medication, was not replaced. Accordingly, a total of 32 volunteers were enrolled in the study. Another subject from group D withdrew consent during Period I. Accordingly, a total of 28 subjects completed the Period I. One subject from group D withdrew consent during Period II. Accordingly, 27 subjects completed the study.

All demographic characteristics of the 32 subjects enrolled in this study were not significantly different among the groups, as summarized in Table 1.

\section{Pharmacokinetics}

All subjects receiving esomeprazole at least once (group $\mathrm{A}, \mathrm{n}=5$; group $\mathrm{B}, \mathrm{n}=8$; group $\mathrm{C}, \mathrm{n}=8$; group $\mathrm{D}, \mathrm{n}=8$ ) were included in the safety analysis. Twenty-eight subjects (group $\mathrm{A}, \mathrm{n}=5$; group $\mathrm{B}, \mathrm{n}=8$; group $\mathrm{C}, \mathrm{n}=8$; group $\mathrm{D}, \mathrm{n}=7$ ) were included in the pharmacokinetic analysis of esomeprazole in Period I, and 27 subjects (group A, $n=5$; group B, $\mathrm{n}=8$; group $\mathrm{C}, \mathrm{n}=8$; group $\mathrm{D}, \mathrm{n}=6$ ) were included in the pharmacokinetic analysis in Period II. 


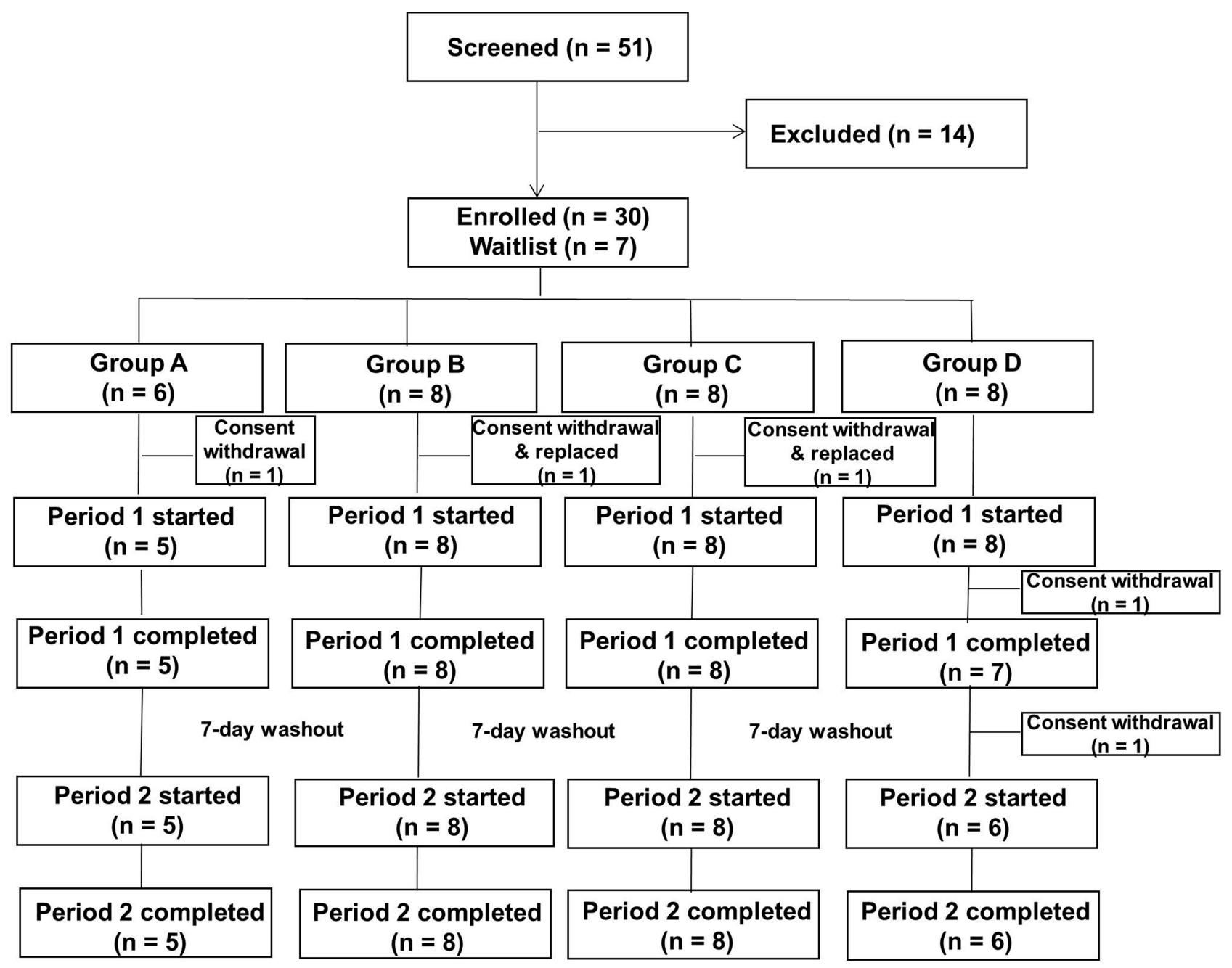

Figure 2 The subject disposition for study screening, enrollment, dosing, and follow-up. Flow diagram illustrating subjects enrolled in the study. Subjects ( $\mathrm{n}=30$ ) were randomized to one of the four groups.

Notes: Group A, 40-mg esomeprazole; Group B, 30-mg YYD60I; Group C, 40-mg YYD60I; Group D, 60-mg YYD60I.

The mean (SD) plasma concentration-time profiles for esomeprazole following single oral dose administration and 5-day repeated dose administration once daily of YYD601 (30-mg, 40-mg, and 60-mg), and 40-mg esomeprazole are illustrated in Figure 3: (A) in fasted state, and (B) in fed state. The major pharmacokinetic parameters of esomeprazole following single and multiple oral doses in fasted states are summarized in Table 2. The GMRs and 90\% CIs of logtransformed, dose-normalized $\mathrm{C}_{\max }$, and AUC for the two treatment groups (YYD601 30-60 mg groups/40-mg esomeprazole group) in fasting conditions were presented in Table 3. The GMRs for log-transformed, dose-normalized AUC for the two treatment groups (YYD601 30-60 mg groups/40-mg esomeprazole group) following single or multiple administration under fasting conditions were $0.9439-1.2277$. The median $\mathrm{T}_{\max }$ and $\mathrm{T}_{\max , \mathrm{ss}}$ values following single and multiple oral administration of 40-mg esomeprazole and YYD601 30-60 mg were $1.50 \mathrm{~h}$ and 4.5-5.4 h, respectively.

The pharmacokinetic parameters of esomeprazole following single and multiple oral doses under fed conditions are shown in Table 4. The GMRs and $90 \%$ CIs of log-transformed $\mathrm{C}_{\max }$ and AUC for the two treatment groups (fed/fast) were presented in Table 5. Food delayed the median $\mathrm{T}_{\max }$ values from 4.5-5.0 $\mathrm{h}$ to 6.0-7.0 h. Single-dose administration of YYD601 30-60 mg with a high-fat meal led to $18-62 \%$ reduction in $\mathrm{C}_{\max }$ and $6-47 \%$ reduction in $\mathrm{AUC}_{\text {last }}$, respectively. Multiple administration of YYD601 30-60 mg with a high-fat meal led to $37-40 \%$ reduction in $\mathrm{C}_{\max }$, and 31-34\% reduction in $\mathrm{AUC}_{\tau}$, respectively. The mean plasma concentration-time profiles for esomeprazole under 
Table I Demographic Characteristics of the 32 Subjects Enrolled in This Study

\begin{tabular}{|c|c|c|c|c|c|}
\hline \multirow[t]{2}{*}{ Characteristics } & \multirow{2}{*}{$\begin{array}{c}\text { Esomeprazole Group } \\
\text { A (40 mg) }\end{array}$} & \multicolumn{3}{|c|}{ YYD60I Group } & \multirow[t]{2}{*}{$p$ value $^{t}$} \\
\hline & & B (30 mg) & C (40 mg) & D (60 mg) & \\
\hline No. of subjects & 6 & 9 & 9 & 8 & \\
\hline \multicolumn{6}{|l|}{ Age, years } \\
\hline Mean (SD) & $26.0(5.40)$ & $27.0(6.36)$ & $25.9(4.46)$ & $30.5(9.96)$ & 0.5149 \\
\hline Minimum-maximum & $20-32$ & $21-38$ & $20-33$ & $21-48$ & \\
\hline \multicolumn{6}{|l|}{ Height, cm } \\
\hline Mean (SD) & $175.8(6.23)$ & $172.6(6.00)$ & I72.5 (4.32) & $171.2(4.45)$ & 0.4612 \\
\hline Minimum-maximum & $168.0-186.4$ & $163.2-181.3$ & $166.5-179.5$ & $|63.9-| 76 . \mid$ & \\
\hline \multicolumn{6}{|l|}{ Weight, kg } \\
\hline Mean (SD) & $72.9(10.5 I)$ & $62.9(8.60)$ & $71.2(5.01)$ & $68.1(8.22)$ & 0.0890 \\
\hline Minimum-maximum & $64.8-92.8$ & $51.3-78.0$ & $64.4-79.1$ & $54.8-78.5$ & \\
\hline \multicolumn{6}{|l|}{ IBW, kg } \\
\hline Mean (SD) & $68.2(5.61)$ & $65.3(5.40)$ & $65.3(3.90)$ & $64.1(4.01)$ & $0.457 \mid$ \\
\hline Minimum-maximum & $61.2-77.8$ & $56.9-73.2$ & $59.9-71.6$ & $57.5-68.5$ & \\
\hline
\end{tabular}

Note: ${ }^{\dagger} p$ value, compared among the four groups by ANOVA.

fasted and fed states are depicted in Figure 4: (A) after single oral administration of YYD601 $40 \mathrm{mg}$, and (B) after 5-day repeated dose administration of YYD601 $40 \mathrm{mg}$.

Dose proportionality was assessed using linear regression analysis for $\mathrm{AUC}_{\mathrm{inf}}, \mathrm{AUC}_{\text {last }}$ or $\mathrm{AUC}_{\tau}$, and $\mathrm{C}_{\max }$ or $\mathrm{C}_{\mathrm{max}, \mathrm{ss}}$ for both a single dose and steady state. The $\mathrm{R}^{2}$ value was at least $85 \%$ for each of these parameters $(0.8554-0.9213$ for single dose, $0.9432-0.9560$ for steady state), indicating that $\mathrm{AUC}$ and $\mathrm{C}_{\max }$ of esomeprazole increased approximately proportionally with the dose, after a single or multiple administration of three increasing doses of YYD601.

\section{Pharmacodynamics}

The mean percentage of time observed for intragastric $\mathrm{pH}>4$ and mean intragastric $\mathrm{pH}$ at baseline (day -1$)$ and on day 5 are presented in Table 6. There were no statistically significant differences in the mean percentage of time observed for intragastric $\mathrm{pH}>4$ at baseline among the four groups (5.6-11.9\% under fasting condition, $6.5-18.9 \%$ under fed condition). Over the 24-hour period after the fifth dose, the mean (SD) percentage of time with intragastric $\mathrm{pH}>4$ on day 5 was significantly increased to $70.5 \%$ (11.0), 75.0\% (6.0), and 74.7\% (15.6) for 30-mg YYD601, 40-mg, and 60-
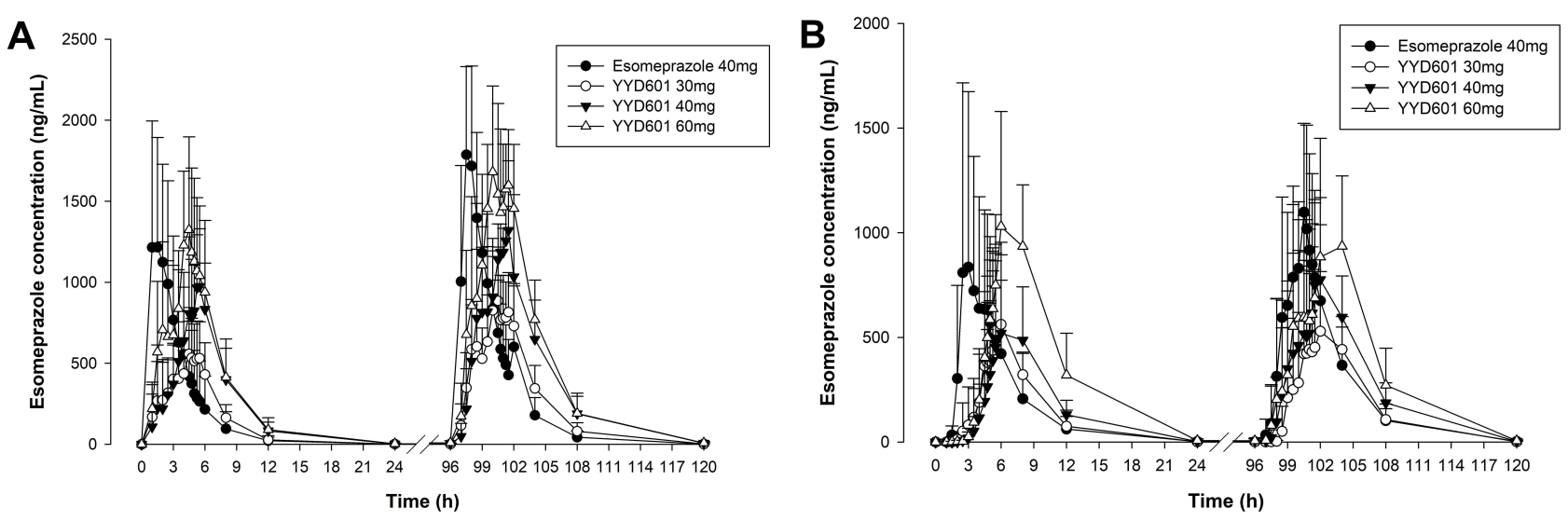

Figure 3 Mean (SD) plasma concentration-time profiles of esomeprazole on day I after a single administration and on day 5 after multiple administrations, in fasting condition (A) and in fed conditions (B).

Note: The vertical bars represent SD. 
Table 2 Esomeprazole Pharmacokinetics Following Single and Multiple Oral Doses in Fasted Healthy Male Subjects

\begin{tabular}{|c|c|c|c|c|c|}
\hline & Parameters & YYD60130 mg & YYD60I 40mg & YYD60I $60 \mathrm{mg}$ & Esomeprazole $40 \mathrm{mg}$ \\
\hline Single-dose & $\begin{array}{l}A \cup C_{\text {last }}\left(h^{*} n g / m L\right) \\
A U C_{\text {inf }}\left(h^{*} n g / m L\right) \\
C_{\max }(n g / m L) \\
T_{\max }(h)^{\dagger} \\
t_{1 / 2}(h)\end{array}$ & $\begin{array}{l}3122.65 \pm 1030.48 \\
3164.23 \pm 1036.83 \\
713.14 \pm 249.96 \\
4.50(3.00-5.50) \\
1.69 \pm 0.67\end{array}$ & $\begin{array}{l}52 \mid 3.59 \pm 1728.58 \\
5319.05 \pm 1758.9 \mid \\
1262.63 \pm 326.87 \\
5.38(4.00-6.00) \\
1.88 \pm 0.54\end{array}$ & $\begin{array}{l}7255.55 \pm 3654.65 \\
73|2.96 \pm 364| .26 \\
\mid 497.33 \pm 431.00 \\
4.50(4.00-6.00) \\
1.83 \pm 0.57\end{array}$ & $\begin{array}{l}4775.48 \pm 2692.79 \\
4787.84 \pm 2687.29 \\
1567.08 \pm 501.44 \\
1.50(1.00-2.50) \\
I .63 \pm 0.62\end{array}$ \\
\hline Multiple-dose & $\begin{array}{l}\mathrm{AUC}_{\tau}\left(\mathrm{h}^{*} \mathrm{ng} / \mathrm{mL}\right) \\
\mathrm{AUC}_{\text {inf }}\left(\mathrm{h}^{*} \mathrm{ng} / \mathrm{mL}\right) \\
\mathrm{C}_{\max , \mathrm{ss}}(\mathrm{ng} / \mathrm{mL}) \\
\mathrm{T}_{\max , \mathrm{ss}}(\mathrm{h})^{\dagger} \\
\mathrm{t}_{\mathrm{I} / 2(\mathrm{~h})}\end{array}$ & $\begin{array}{l}5667.40 \pm 1583.08 \\
5545.60 \pm 1608.73 \\
1071.31 \pm 237.85 \\
4.50(4.00-6.00) \\
1.98 \pm 0.45\end{array}$ & $\begin{array}{l}8679.28 \pm 1489.44 \\
8595.54 \pm 1574.12 \\
1501.19 \pm 355.69 \\
5.00(4.00-5.50) \\
2.34 \pm 0.38\end{array}$ & $\begin{array}{l}1 \mathrm{I}, 464.54 \pm 3142.05 \\
1 \mathrm{I}, 408.11 \pm 3244.92 \\
1911.48 \pm 373.83 \\
4.50(3.50-6.00) \\
2.18 \pm 0.54\end{array}$ & $\begin{array}{l}7172.08 \pm 1764.18 \\
7129.65 \pm 1774.62 \\
2029.31 \pm 416.42 \\
1.50(1.00-2.00) \\
1.90 \pm 0.50\end{array}$ \\
\hline
\end{tabular}

Note: Data are presented as mean \pm SD except for $\mathrm{T}_{\max }$ values as median (minimum-maximum) ${ }^{\dagger}$.

Abbreviations: $\mathrm{AUC}_{\text {last }}$, area under the plasma concentration-time curve from time zero to the last measurable time; $A \cup C_{\text {inf, }}$ area under the plasma concentration-time curve from time zero to infinity; $C_{\max }$, maximum plasma concentration; $T_{\max }$, time to reach $C_{\max } ; t_{1 / 2}$, terminal elimination half-life; $A U C_{\tau}$, area under the plasma concentration-time curve during a dosing interval $(\tau)$ at steady state; $C_{\max }$, ss, maximum plasma concentration at steady state; $T_{\max }$, ss, time to reach $C_{\max }$ ss.

Table 3 Geometric Mean Ratio $\left(90 \%\right.$ Cls) for the Log-Transformed Dose-Normalized AUC last $/$ AUC $_{\tau}$ and $C_{\max }$ Following Single or Multiple Administration of YYD60I (30 mg, $40 \mathrm{mg}$, and $60 \mathrm{mg}$ ) versus 40-mg Esomeprazole in Fasted Healthy Male Subjects

\begin{tabular}{|c|c|c|c|c|}
\hline & \multicolumn{2}{|c|}{ Single Dose } & \multicolumn{2}{|c|}{ Multiple Dose } \\
\hline & Parameters & $\begin{array}{c}\text { Geometric Mean Ratio } \\
(90 \% \mathrm{Cl})\end{array}$ & Parameters & $\begin{array}{c}\text { Geometric Mean Ratio } \\
(90 \% \mathrm{Cl})\end{array}$ \\
\hline YYD60I 30 mg/ esomeprazole & $\mathrm{C}_{\max } /$ dose & $0.5845(0.3904-0.8752)$ & $\mathrm{C}_{\max } / \mathrm{dose}$ & $0.7000(0.5595-0.8755)$ \\
\hline $40 \mathrm{mg}$ & $A \cup C_{\text {last }} /$ dose & $0.9439(0.5947-1.4982)$ & $\mathrm{AUC}_{\tau} /$ dose & $1.0480(0.8015-1.3704)$ \\
\hline YYD60I 40 mg/ esomeprazole & $\mathrm{C}_{\max } /$ dose & $0.8078(0.6020-1.0840)$ & $\mathrm{C}_{\max } /$ dose & $0.7367(0.5965-0.9099)$ \\
\hline $40 \mathrm{mg}$ & $A \cup C_{\text {last }} /$ dose & I.I76I (0.7320-I.8897) & $\mathrm{AUC}_{\tau} /$ dose & I.2277 (0.9984-I.5096) \\
\hline YYD60I 60 mg/ esomeprazole & $\mathrm{C}_{\max } /$ dose & $0.6330(0.4533-0.8840)$ & $\mathrm{C}_{\max } /$ dose & $0.6278(0.5077-0.7765)$ \\
\hline $40 \mathrm{mg}$ & $A \cup C_{\text {last }} /$ dose & $1.0196(0.5558-1.8703)$ & $\mathrm{AUC}_{\tau} /$ dose & $1.0629(0.8108-1.3934)$ \\
\hline
\end{tabular}

Abbreviations: $C_{\max }$, maximum plasma concentration; $A \cup C_{\text {last }}$, area under the plasma concentration-time curve from time zero to the last measurable time; $A U C_{\tau}$, area under the plasma concentration-time curve during a dosing interval $(\tau)$ at steady state.

Table 4 Esomeprazole Pharmacokinetics Following Single and Multiple Oral Doses in Fed Healthy Male Subjects

\begin{tabular}{|c|c|c|c|c|c|}
\hline & Parameters & YYD60I $30 \mathrm{mg}$ & YYD60I 40mg & YYD60I $60 \mathrm{mg}$ & Esomeprazole $40 \mathrm{mg}$ \\
\hline Single-dose & $\begin{array}{l}A \cup C_{\text {last }}\left(h^{*} \mathrm{ng} / \mathrm{mL}\right) \\
A \cup C_{\text {inf }}\left(h^{*} \mathrm{ng} / \mathrm{mL}\right) \\
\mathrm{C}_{\max }(\mathrm{ng} / \mathrm{mL}) \\
\mathrm{T}_{\max }(\mathrm{h})^{\dagger} \\
\mathrm{t}_{1 / 2}(\mathrm{~h})\end{array}$ & $\begin{array}{l}2803.46 \pm 1451.67 \\
3075.48 \pm 1271.79 \\
637.05 \pm 377.07 \\
6.00(4.50-8.00) \\
2.41 \pm 1.28\end{array}$ & $\begin{array}{l}3533.17 \pm 2405.71 \\
4059.18 \pm 2152.91 \\
597.12 \pm 400.40 \\
7.00(5.50-12.00) \\
2.00 \pm 0.34\end{array}$ & $\begin{array}{l}7395.03 \pm 2334.33 \\
7567.58 \pm 2162.89 \\
1210.05 \pm 445.41 \\
8.00(6.00-8.00) \\
2.17 \pm 0.43\end{array}$ & $\begin{array}{l}4156.16 \pm 3187.55 \\
4168.10 \pm 3189.99 \\
1138.87 \pm 694.20 \\
3.00(2.50-5.00) \\
I .66 \pm 0.65\end{array}$ \\
\hline Multiple-dose & $\begin{array}{l}\mathrm{AUC}_{\tau}\left(\mathrm{h}^{*} \mathrm{ng} / \mathrm{mL}\right) \\
\mathrm{AUC}_{\text {inf }}\left(\mathrm{h}^{*} \mathrm{ng} / \mathrm{mL}\right) \\
\mathrm{C}_{\max , \mathrm{ss}}(\mathrm{ng} / \mathrm{mL}) \\
\mathrm{T}_{\max , \mathrm{ss}}(\mathrm{h})^{\dagger} \\
\mathrm{t}_{1 / 2}(\mathrm{~h})\end{array}$ & $\begin{array}{l}3907.49 \pm 1162.09 \\
3739.51 \pm 1232.43 \\
711.45 \pm 314.67 \\
6.00(4.50-8.00) \\
1.96 \pm 0.37\end{array}$ & $\begin{array}{l}5955.09 \pm 1862.59 \\
5767.24 \pm 1973.46 \\
944.60 \pm 364.83 \\
6.00(4.00-8.00) \\
2.19 \pm 0.41\end{array}$ & $\begin{array}{l}8049.98 \pm 2491.72 \\
7852.49 \pm 2722.19 \\
1226.23 \pm 409.50 \\
7.00(4.75-8.00) \\
2.25 \pm 0.49\end{array}$ & $\begin{array}{l}5843.39 \pm 1632.78 \\
5824.36 \pm 1673.29 \\
1316.38 \pm 238.74 \\
4.50(2.50-4.75) \\
1.99 \pm 0.50\end{array}$ \\
\hline
\end{tabular}

Note: Data are presented as mean \pm SD except for $T_{\max }$ values as median (minimum-maximum) ${ }^{\dagger}$.

Abbreviations: $\mathrm{AUC}_{\text {last }}$, area under the plasma concentration-time curve from time zero to the last measurable time; $A U C_{\text {inf, }}$ area under the plasma concentration-time curve from time zero to infinity; $C_{\max }$, maximum plasma concentration; $T_{\max }$, time to reach $C_{\max } ; t_{1 / 2}$, terminal elimination half-life; $A U C_{\tau}$, area under the plasma concentration-time curve during a dosing interval $(\tau)$ at steady state; $C_{\max , ~ s s}$, maximum plasma concentration at steady state; $T_{\text {max, ss }}$, time to reach $C_{\max }$ ss. 
Table 5 Geometric Mean Ratio ( $90 \%$ Cls) for the Log-Transformed (Fed/Fasting) AUC last $/ A \cup C_{\tau}$ and $C_{\text {max }}$ Following Single or Multiple Administration of YYD60I (30 mg, $40 \mathrm{mg}$, and $60 \mathrm{mg}$ ) in Healthy Male Subjects

\begin{tabular}{|c|c|c|c|c|}
\hline & \multicolumn{2}{|r|}{ Single Dose } & \multicolumn{2}{|r|}{ Multiple Dose } \\
\hline & Parameters & Geometric Mean Ratio $(90 \% \mathrm{Cl})$ & Parameters & Geometric Mean Ratio $(90 \% \mathrm{Cl})$ \\
\hline \multirow[t]{2}{*}{ YYD60I $30 \mathrm{mg}$} & $\mathrm{C}_{\max }$ & $0.8224(0.577|-| .|7| 8)$ & $\mathrm{C}_{\max }$ & $0.6254(0.4477-0.8737)$ \\
\hline & $A \cup C_{\text {last }}$ & $0.8444(0.6901-1.0333)$ & $\mathrm{AUC}_{\tau}$ & $0.6862(0.5257-0.8957)$ \\
\hline \multirow[t]{2}{*}{ YYD60I $40 \mathrm{mg}$} & $\mathrm{C}_{\max }$ & $0.3842(0.2176-0.6781)$ & $\mathrm{C}_{\max }$ & $0.5965(0.4535-0.7847)$ \\
\hline & $\mathrm{AUC}_{\text {last }}$ & $0.5330(0.3063-0.9274)$ & $\mathrm{AUC}_{\tau}$ & $0.6669(0.5807-0.7658)$ \\
\hline \multirow[t]{2}{*}{ YYD60I $60 \mathrm{mg}$} & $\mathrm{C}_{\max }$ & $0.7 \mid 36(0.484|-1.05| 8)$ & $\mathrm{C}_{\max }$ & $0.5965(0.4747-0.8158)$ \\
\hline & $A \cup C_{\text {last }}$ & $0.9427(0.814 \mid-1.0916)$ & $\mathrm{AUC}_{\tau}$ & $0.6593(0.522 \mathrm{I}-0.9208)$ \\
\hline
\end{tabular}

Abbreviations: $C_{\max }$, maximum plasma concentration; $A \cup C_{\text {last }}$, area under the plasma concentration-time curve from time zero to the last measurable time; $A U C_{\tau}$, area under the plasma concentration-time curve during a dosing interval $(\tau)$ at steady state.

mg groups, respectively ( $p<0.0001$ for all three groups) that were comparable to that $(75.1 \%(9.4))$ for the 40 -mg esomeprazole group, with no statistically significant differences among the groups.

There were no statistically significant differences in mean intragastric $\mathrm{pH}$ at baseline among the four groups. After oral administration of YYD601 or esomeprazole, the mean intragastric $\mathrm{pH}$ was significantly elevated in the subjects across all groups, with no statistically significant difference between the three different doses of YYD601 and esomeprazole $40 \mathrm{mg}$. The 24-hour intragastric mean $\mathrm{pH}$ profiles at baseline (day -1 ) and after the fifth dose (day 5 ) of YYD601 30-60 mg or 40-mg esomeprazole DR are presented in Figure 5.
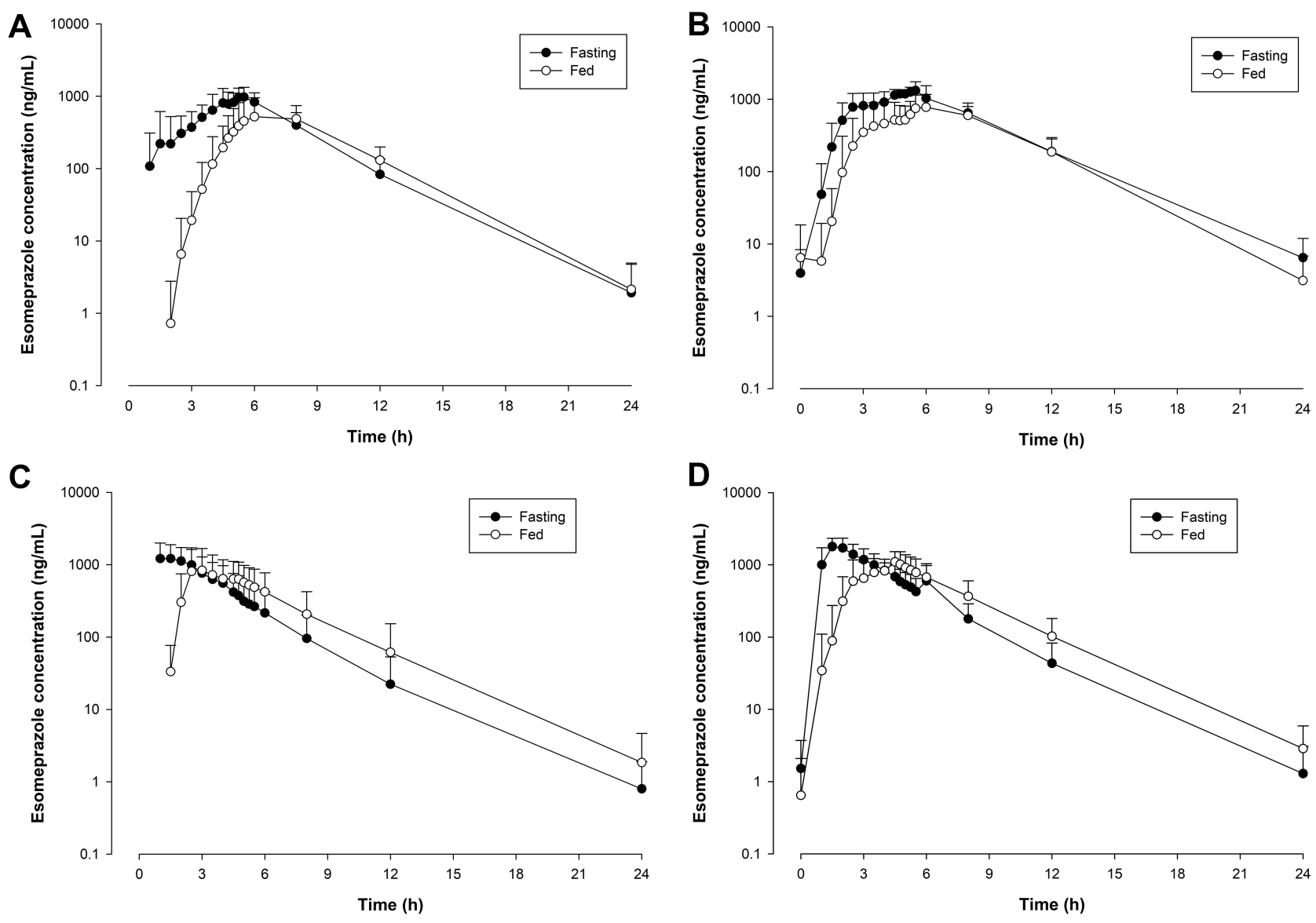

Figure 4 Mean plasma concentration-time profiles of esomeprazole under fasting and fed conditions after single (A) and multiple (B) oral administration of YYD60I 40 mg, and after single (C) and multiple (D) administration of 40-mg esomeprazole. 
Table 6 The Change in Percentage of Time with the Intragastric $\mathrm{pH}>4$ and Mean Intragastric $\mathrm{pH}$ for $24 \mathrm{~h}$ and During Night-Time After Multiple Administration of YYD 601 30-60 mg and 40-mg Esomeprazole

\begin{tabular}{|c|c|c|c|c|c|c|c|}
\hline & & & & \multicolumn{3}{|c|}{ YYD60I } & \multirow{2}{*}{$\begin{array}{c}\text { Esomeprazole } \\
40 \mathrm{mg}\end{array}$} \\
\hline & & & & $30 \mathrm{mg}$ & $40 \mathrm{mg}$ & $60 \mathrm{mg}$ & \\
\hline \multirow[t]{4}{*}{ Fasting condition } & \multirow[t]{2}{*}{$\begin{array}{l}\text { Mean } \% \text { of time } \\
\text { with } \mathrm{pH}>4\end{array}$} & For 24 hours & $\begin{array}{l}\text { Day }-1 \\
\text { Day } 5 \\
\text { p value* }\end{array}$ & $\begin{array}{l}5.6 \pm 4.2 \\
70.5 \pm 11.0 \\
<0.0001\end{array}$ & $\begin{array}{l}11.9 \pm 10.5 \\
75.0 \pm 6.0 \\
<0.0001\end{array}$ & $\begin{array}{l}8.3 \pm 6.9 \\
74.7 \pm 15.6 \\
<0.0001\end{array}$ & $\begin{array}{l}10.2 \pm 4.3 \\
75.1 \pm 9.4 \\
0.0001\end{array}$ \\
\hline & & Night-time ${ }^{\ddagger}$ & $\begin{array}{l}\text { Day }-1 \\
\text { Day } 5 \\
\text { p value* }\end{array}$ & $\begin{array}{l}3.3 \pm 5.8 \\
54.6 \pm 21.8 \\
0.0117^{\dagger}\end{array}$ & $\begin{array}{l}2.0 \pm 2.4 \\
60.8 \pm 16.5 \\
<0.0001\end{array}$ & $\begin{array}{l}1.8 \pm 3.6 \\
60.1 \pm 27.7 \\
0.0180^{\dagger}\end{array}$ & $\begin{array}{l}2.8 \pm 4.6 \\
55.0 \pm 19.3 \\
0.0431^{\dagger}\end{array}$ \\
\hline & \multirow[t]{2}{*}{ Mean $\mathrm{pH}$} & For 24 hours & $\begin{array}{l}\text { Day }-I \\
\text { Day } 5 \\
p \text { value* }\end{array}$ & $\begin{array}{l}2.0 \pm 0.3 \\
5.1 \pm 0.5 \\
<0.0001\end{array}$ & $\begin{array}{l}2.3 \pm 0.5 \\
5.5 \pm 0.3 \\
<0.0001\end{array}$ & $\begin{array}{l}2.2 \pm 0.5 \\
5.4 \pm 0.7 \\
<0.0001\end{array}$ & $\begin{array}{l}2.3 \pm 0.2 \\
5.3 \pm 0.4 \\
0.0001\end{array}$ \\
\hline & & Night-time ${ }^{\ddagger}$ & $\begin{array}{l}\text { Day }-1 \\
\text { Day } 5 \\
p \text { value* }\end{array}$ & $\begin{array}{l}1.7 \pm 0.4 \\
4.5 \pm 1.0 \\
<0.0001\end{array}$ & $\begin{array}{l}1.6 \pm 0.3 \\
4.8 \pm 0.9 \\
<0.0001\end{array}$ & $\begin{array}{l}1.7 \pm 0.4 \\
4.6 \pm 1.2 \\
0.0009\end{array}$ & $\begin{array}{l}1.7 \pm 0.2 \\
4.4 \pm 0.7 \\
0.0005\end{array}$ \\
\hline \multirow[t]{4}{*}{ Fed condition } & \multirow[t]{2}{*}{$\begin{array}{l}\text { Mean } \% \text { of time } \\
\text { with } \mathrm{pH}>4\end{array}$} & For 24 hours & $\begin{array}{l}\text { Day II } \\
\text { Day I6 } \\
\text { p value* }\end{array}$ & $\begin{array}{l}6.6 \pm 4.9 \\
69.0 \pm 7.1 \\
<0.0001\end{array}$ & $\begin{array}{l}18.9 \pm 12.4 \\
77.7 \pm 12.6 \\
0.0117^{\dagger}\end{array}$ & $\begin{array}{l}6.5 \pm 3.9 \\
75.7 \pm 13.7 \\
0.0277^{\dagger}\end{array}$ & $\begin{array}{l}15.1 \pm 6.2 \\
80.2 \pm 13.0 \\
0.0001\end{array}$ \\
\hline & & Night-time ${ }^{\ddagger}$ & $\begin{array}{l}\text { Day II } \\
\text { Day I6 } \\
p \text { value* }\end{array}$ & $\begin{array}{l}5.4 \pm 6.4 \\
50.4 \pm 12.9 \\
0.0117^{\dagger}\end{array}$ & $\begin{array}{l}9.1 \pm 12.9 \\
59.9 \pm 20.2 \\
0.0117^{\dagger}\end{array}$ & $\begin{array}{l}7.6 \pm 5.7 \\
59.7 \pm 25.5 \\
0.0277^{\dagger}\end{array}$ & $\begin{array}{l}16.9 \pm 8.2 \\
63.4 \pm 26.1 \\
0.0078\end{array}$ \\
\hline & \multirow[t]{2}{*}{ Mean $\mathrm{pH}$} & For 24 hours & $\begin{array}{l}\text { Day II } \\
\text { Day I6 } \\
\text { p value* }\end{array}$ & $\begin{array}{l}2.1 \pm 0.4 \\
5.0 \pm 0.5 \\
<0.0001\end{array}$ & $\begin{array}{l}2.6 \pm 0.6 \\
5.5 \pm 0.6 \\
<0.0001\end{array}$ & $\begin{array}{l}2.1 \pm 0.3 \\
5.3 \pm 0.5 \\
<0.0001\end{array}$ & $\begin{array}{l}2.6 \pm 0.4 \\
5.6 \pm 1.0 \\
0.0021\end{array}$ \\
\hline & & Night-time ${ }^{\ddagger}$ & $\begin{array}{l}\text { Day II } \\
\text { Day } 16 \\
p \text { value* }\end{array}$ & $\begin{array}{l}1.8 \pm 0.5 \\
4.3 \pm 0.8 \\
0.0001\end{array}$ & $\begin{array}{l}2.0 \pm 0.7 \\
4.8 \pm 1.2 \\
<0.0001\end{array}$ & $\begin{array}{l}1.9 \pm 0.4 \\
4.7 \pm 1.2 \\
0.0009\end{array}$ & $\begin{array}{l}2.4 \pm 0.4 \\
5.0 \pm 1.3 \\
0.0058\end{array}$ \\
\hline
\end{tabular}

Notes: *Compared between the two groups (before and after 5 -day administration) by paired $t$-test or Wilcoxon signed rank test ${ }^{\dagger .}{ }^{\dagger}$ The night-time was defined as the time period between $1 \mathrm{I} \mathrm{pm}$ and $8 \mathrm{am}$. Data are presented as mean \pm SD.

Mean serum gastrin concentrations were significantly increased following multiple administrations of YYD601 and esomeprazole in all four groups, from $18.4-27.8 \mathrm{pg} / \mathrm{mL}$ at baseline (on day -1 ) to $42.3-97.9 \mathrm{pg} / \mathrm{mL}$ on day 5 (p value $<$ 0.05), with no significant differences between YYD601 and esomeprazole $40 \mathrm{mg}$, or among the three YYD601 groups.

\section{Safety}

All 29 subjects who received at least one dose of the study drug were included in the safety assessment. A total of 11 TEAEs were observed in nine subjects (31.0\%) during the study period, as presented in Table 7. Of these 11 TEAEs, nine events (30-mg YYD601 group: protein urine present, one event; 40-mg YYD601 group: protein urine present, two events; upper respiratory infection, two events; ALT increased, one event; headache, one event; 60-mg YYD601 group: diarrhea, one event; headache, one event) were thought to be possibly related to the study drug. Most AEs were of mild severity, with one moderate event of increased bilirubin, observed after the use of 30-mg YYD601. All AEs were resolved without therapy. No serious TEAEs occurred during the study. 


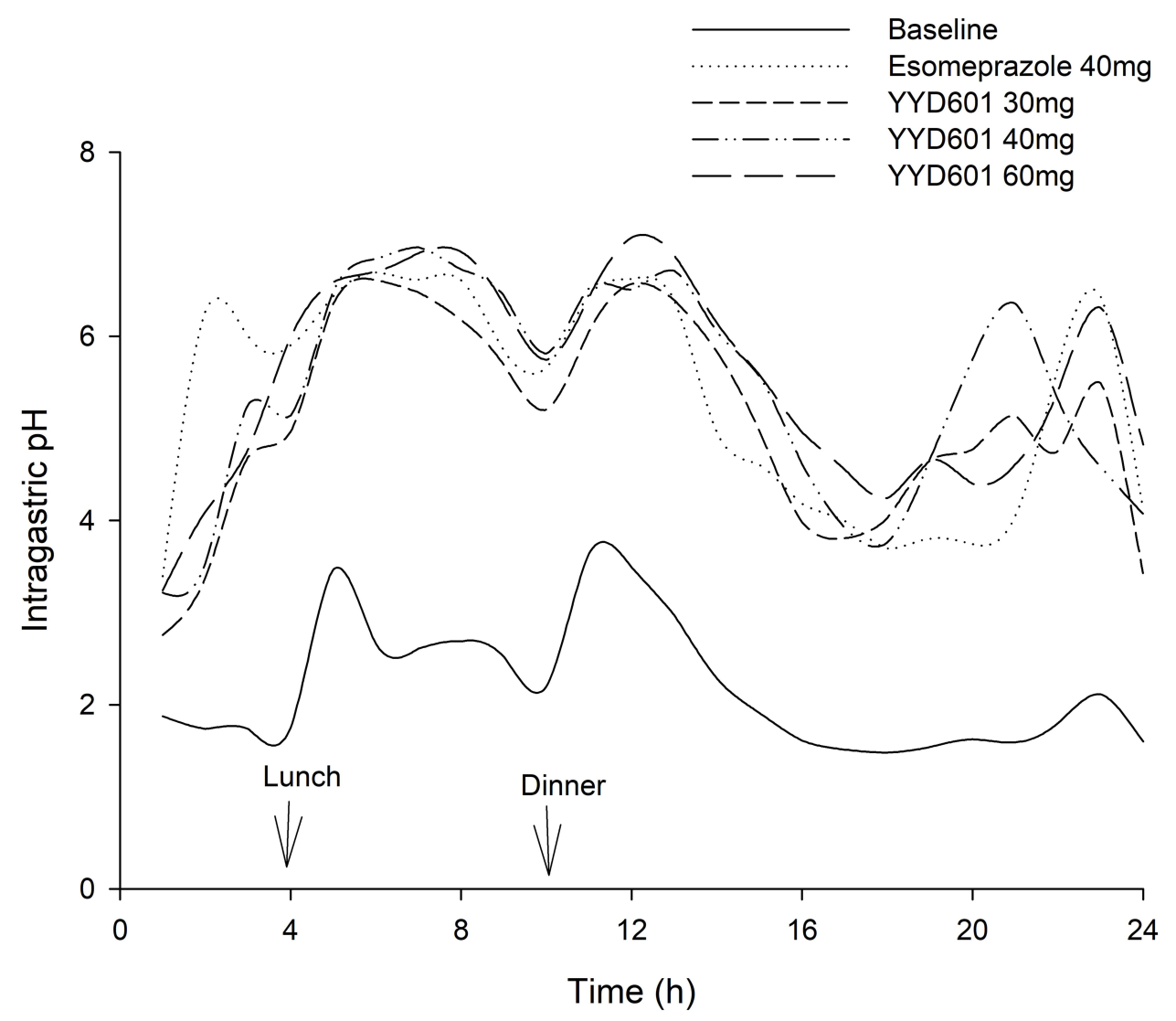

Figure 5 Mean intragastric pH measurements over a 24-h interval at baseline and with 30, 40, and 60-mg YYD60I and 40-mg esomeprazole in healthy subjects after 5-day multiple administrations in fasting condition, to depict the sequential time course of intragastric $\mathrm{pH}$ recorded in the study. On the $24-\mathrm{h}$ scale, the $\mathrm{x}$-axis shows $0 \mathrm{~h}$ (hour $8: 00$ on day 5 to 24 h (hour 8:00 on day six).

\section{Discussion}

In this study, we evaluated the pharmacokinetic and pharmacodynamic characteristics of YYD601 in the context of single and multiple oral administration, under fasted and fed conditions, and compared them with the original esomeprazole administration. YYD601 administration was safe and well-tolerated during the study, with AEs of mild severity.

From a series of non-clinical pharmacokinetics and efficacy studies conducted in Beagles to compare the efficacy of YYD601 to that of esomeprazole $40 \mathrm{mg}$, the $C_{\max }$ value after administration of YYD601 $40 \mathrm{mg}$ was similar to that observed for esomeprazole $40 \mathrm{mg}$ and the AUC value was 1.5 times higher than that after administration of esomeprazole $40 \mathrm{mg}$, with the superior acid suppression effect of YYD601 to that of esomeprazole $40 \mathrm{mg}$. Consequently, $40 \mathrm{mg}$ was selected as the standard dose of YYD601 to evaluate the efficacy of the new DDR formulation compared to that of the original esomeprazole DR formulation at the same dose. Furthermore, two more doses, $30 \mathrm{mg}$ and $60 \mathrm{mg}$, were selected as the minimum dose and higher dose. Accordingly, three different doses of YYD601 (30 mg, $40 \mathrm{mg}$, and $60 \mathrm{mg}$ ) were selected in this study to evaluate the tolerable dose through Phase I pharmacokinetic/pharmacodynamics studies.

YYD601 was designed as a DDR formulation of esomeprazole with a mixture of two types of granules released in two discrete phases to maintain plasma concentrations over a longer period than conventional formulation. In this study, the characteristic double peaks were observed in most of the individual plasma concentration-time profiles of esomeprazole following once-daily single or multiple administration of 30-mg, 40-mg, or 60-mg YYD601 capsules, compared with the single peaks seen in those following administration of conventional formulation. The representative individual plasma concentration-time profiles of esomeprazole obtained from one subject following YYD601 $40 \mathrm{mg}$ administration and that obtained from another subject administered with esomeprazole $40 \mathrm{mg}$ are shown in Figure $6 \mathrm{~A}$ and $\mathrm{B}$, respectively. Most of the first peaks occurred approximately 1-3 $\mathrm{h}$ after dosing, similar to those $\mathrm{T}_{\max }$ values observed for the conventional formulations $(1-2.5 \mathrm{~h})$, and most of the second peaks occurred $3-6 \mathrm{~h}$ after dosing. The median $\mathrm{T}_{\max }$ 
Table 7 Adverse Events That Were Reported After Multiple Oral Administration of YYD60I 30-60 mg and 40-mg Esomeprazole in 29 Healthy Subjects

\begin{tabular}{|c|c|c|c|c|c|}
\hline $\begin{array}{l}\text { Adverse Event by System Organ Class } \\
\text { and Preferred Term }\end{array}$ & $\begin{array}{l}\text { YYD60I } \\
30 \mathrm{mg}(\mathrm{n}=8)\end{array}$ & $\begin{array}{c}\text { YYD60 I } \\
40 \mathrm{mg}(\mathrm{n}=8)\end{array}$ & $\begin{array}{c}\text { YYD60I } \\
60 \mathrm{mg}(\mathrm{n}=8)\end{array}$ & $\begin{array}{l}\text { Esomeprazole } \\
40 \mathrm{mg}(\mathrm{n}=5)\end{array}$ & Total \\
\hline Total number of subjects [number of events] & $2[2]$ & $5[6]$ & $2[3]$ & & $9[\mathrm{II}]$ \\
\hline $\begin{array}{l}\text { Investigations } \\
\text { ALT increased } \\
\text { Blood bilirubin increased } \\
\text { Blood cholesterol increased } \\
\text { Protein urine present } \\
\text { Gastrointestinal disorders } \\
\text { Diarrhea } \\
\text { Nervous system disorder } \\
\text { Headache } \\
\text { Respiratory, thoracic and mediastinal disorders } \\
\text { Upper respiratory tract infection }\end{array}$ & $\begin{array}{l}\text { I [I] } \\
\text { I [I] }\end{array}$ & $\begin{array}{l}\text { I [I] } \\
2 \text { [2] }\end{array}$ & $\begin{array}{l}\mathrm{I}[\mathrm{I}] \\
\mathrm{I}[\mathrm{I}] \\
\mathrm{I}[\mathrm{I}]\end{array}$ & & $\begin{array}{l}\mathrm{I}[\mathrm{I}] \\
\mathrm{I}[\mathrm{I}] \\
\mathrm{I}[\mathrm{I}] \\
3[3] \\
\mathrm{I}[\mathrm{I}] \\
2[2] \\
2[2]\end{array}$ \\
\hline
\end{tabular}

Abbreviation: ALT, alanine aminotransferase.

values of YYD601 were delayed compared with those for the conventional formulation. The mean residence time values for YYD601 following oral administration in fasting conditions are 5.2 to $6.3 \mathrm{~h}$, compared with 3.0 to $3.7 \mathrm{~h}$ for conventional esomeprazole, which indicates that YYD601 DDR formulation extends the duration of drug exposure. Accordingly, the use of this YYD601 formulation of esomeprazole can achieve more prolonged plasma concentration, leading to an extended period of acid suppression with a single daily dose.

The increase of the AUC values of esomeprazole by 1.6-1.8 times after repeated once-daily dosing with 30-60 mg in the present study was compatible with those from the study by Kim et al who reported that the AUC value after repeated once-daily dosing with $20 \mathrm{mg}$ was increased by $80 \%$ compared to that after a single dose. ${ }^{15}$ Hassan-Alin et al reported that once-daily dosing of $20 \mathrm{mg}$ or $40 \mathrm{mg}$ esomeprazole for 5 days increased the geometric mean AUC by $90 \%$ or $159 \%$, with absolute bioavailability increased from $50 \%$ to $68 \% .{ }^{23}$ The plausible explanations for AUC increase at steady state were reduced systemic clearance and reduced first-pass metabolism following repeated administration. ${ }^{10}$

Single-dose administration of YYD601 30-60 mg with a high-fat meal led to $18-62 \%$ reduction in $\mathrm{C}_{\max }$ and 6-47\% reduction in $\mathrm{AUC}_{\text {last }}$, respectively. Multiple administration of YYD601 30-60 mg with a high-fat meal led to 37-40\% reduction in $\mathrm{C}_{\max }$, and 31-34\% reduction in $\mathrm{AUC}_{\tau}$, respectively, and postponed $\mathrm{T}_{\max }$ from $4.5-5.0 \mathrm{~h}$ to $6.0-7.0 \mathrm{~h}$. The
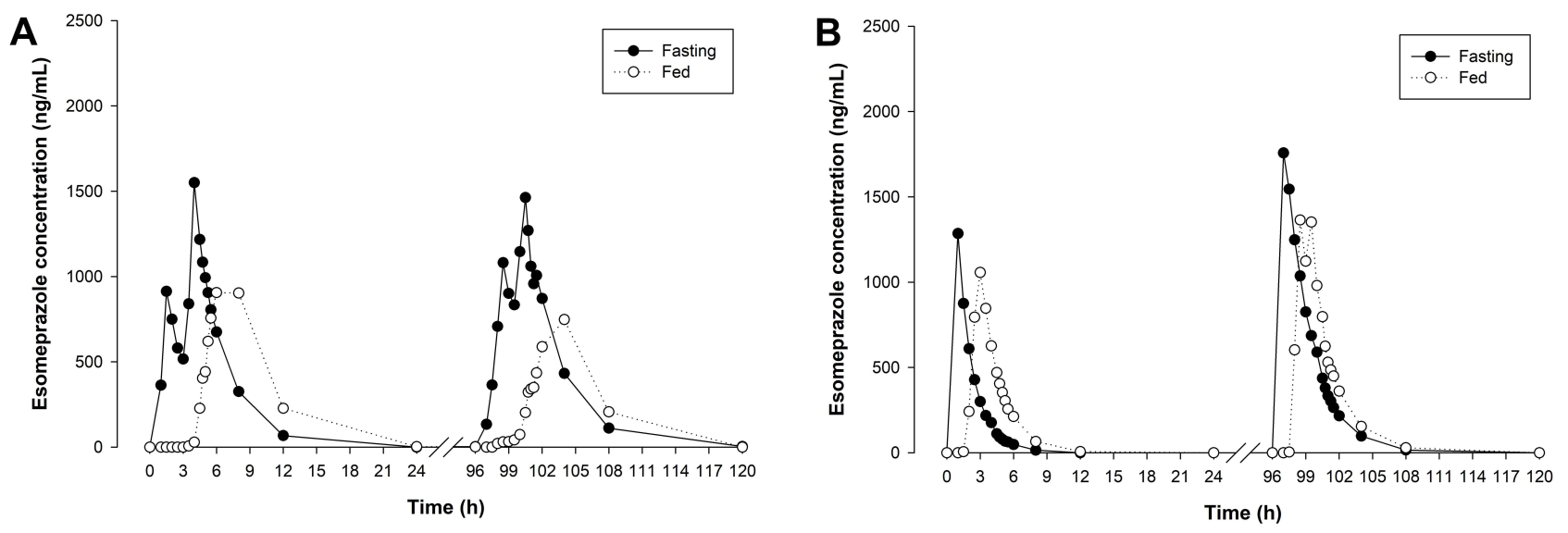

Figure 6 The representative individual plasma concentration-time profile of esomeprazole obtained from one subject following single and multiple administrations of YYD60I $40 \mathrm{mg}$ (A) and that obtained from another subject administered with esomeprazole $40 \mathrm{mg}$ (B). 
elimination process was not relatively affected by food intake, and the terminal half-life remained consistent. The increase in $\mathrm{T}_{\max }$ with a high-fat meal in our study might be due to its delayed gastric emptying, and the high fat meals could increase the gut $\mathrm{pH}$ and therefore cause a decrease in bioavailability of esomeprazole, resulting in the reduction in $\mathrm{C}_{\max }$ and AUC.

The pharmacodynamic characteristics of esomeprazole following multiple oral administration of YYD601 30-60 mg or a standard dose $(40 \mathrm{mg})$ of esomeprazole were evaluated based on the percentage of time that intragastric $\mathrm{pH}$ is maintained $>4$ over a $24-\mathrm{h}$ period after dosing. In this study, the mean percentage of time with intragastric $\mathrm{pH}>4$ was $75.1 \%$, and the mean 24-h intragastric $\mathrm{pH}$ was 5.3 after oral administration of 40-mg esomeprazole, comparable to those reported by Lind et al. ${ }^{24}$ After oral administration of YYD601 30-60 mg or 40-mg esomeprazole for 5 days, the significantly higher percentage of time with intragastric $\mathrm{pH}>4$ over a 24-h period from baseline was observed in all groups (p-value for all three YYD601 groups, < 0.0001; for esomeprazole, 0.0001), with no significant differences between three different dose groups of YYD601 and the conventional formulation, or among the four groups.

There was no obvious correlation between $\mathrm{AUC}_{\tau}$ and the baseline-adjusted percentage of time with the intragastric $\mathrm{pH}>4$ during the 24-h period after multiple administration of YYD601 in this study. There were no statistically significant differences in the percentage of time with the intragastric $\mathrm{pH}>4$ during the 24-h period after multiple administrations among the three different YYD601 groups. It is comparable to the study results by Metz et al who reported that the values for mean 24-h intragastric $\mathrm{pH}$ and the mean percentage of time with the intragastric $\mathrm{pH}>4$ showed no significant differences among the three dose groups, after multiple oral administration of dexlansoprazole MR 60,90 , and $120 \mathrm{mg}^{9}{ }^{9}$ PPIs can irreversibly inhibit only secreting proton pump molecules in the gastric parietal cells by covalent binding, and thus inhibit gastric acid secretion. ${ }^{25}$ As not all the pumps are active during the short plasma halflife of most PPIs (about 1-2 h), only 70\% of the pump enzymes are inhibited, with about 2 to 3 days taken to reach steady state inhibition of acid secretion. ${ }^{25}$ Furthermore, because the half-life of new pump biosynthesis is about $54 \mathrm{~h}$, about $20 \%$ of pumps are newly synthesized over a 24 -hour period. ${ }^{25}$ Accordingly, increasing the dose has substantially no effect once optimal dosage has been reached. ${ }^{25}$

As most PPIs have a relatively short plasma half-life, increasing the once-daily dose or increasing dosing frequency, including bedtime dosing, could not be sufficient to effectively control NAB, the main cause of night-time heartburn. ${ }^{8,26}$ In this study, the mean percentage of time with intragastric $\mathrm{pH}>4$ during night-time (from $11 \mathrm{pm}$ on day 5 to 8 am on day 6) was significantly increased from baseline after the oral administration of 30-mg YYD601, 40-mg and 60-mg (p-value $=0.0117,<0.0001$, and 0.0180, respectively), and 40-mg esomeprazole (p-value $=0.0431$ ) under fasting condition, with no statistically significant difference between the three YYD601 groups and 40-mg esomeprazole. Furthermore, the mean intragastric $\mathrm{pH}$ values during night-time were higher after 5-day dosing of YYD601 30$60 \mathrm{mg}$, than those after dosing of 40-mg esomeprazole, as illustrated in Figure 5. In the 24-h intragastric pH-time profiles, the mean $\mathrm{pH}$ values of YYD601, especially from 2 am to 6 am (from $18 \mathrm{~h}$ to $22 \mathrm{~h}$ after dosing) were much higher $(\mathrm{pH}>4$ ) and increased to a maximum $\mathrm{pH}$ of more than 6 , compared with those of esomeprazole (within a range of approximately $\mathrm{pH} 3.5-5$ ). Although we set the time period for the night-time from $11 \mathrm{pm}$ to $8 \mathrm{am}$ in our study, it is not strictly defined, but variable from $10 \mathrm{pm}$ to $9 \mathrm{am}$, according to the study protocols. When the time period for the nighttime was reset to $10 \mathrm{pm}-6$ am in our study, the mean intragastric $\mathrm{pH}$ value were significantly higher after 5-day dosing of YYD601 40mg, compared to that after dosing of 40-mg esomeprazole (p-value $=0.030$ ). Accordingly, YYD601, a new dual delayed-release formulation of esomeprazole, can more reliably control NAB and night-time symptoms, such as heartburn, with once-daily dosing, even with the lower dose, compared with the conventional formulation.

Although the integrated gastric acidity had not been included in the pharmacodynamic parameters predetermined in our study protocol, it was calculated using the $\mathrm{pH}$ data for one-second intervals as described previously in other studies to evaluate the acid suppression effect. ${ }^{27}$ The percent decrease values of integrated gastric acidity from baseline for $24 \mathrm{~h}$ and during night-time after administration of YYD601 30-60 mg for 5 days were 89.0-91.0\%, and 89.8-92.8\%, respectively, compared with those values for 5-day 40 -mg esomeprazole ( $90.5 \%$ and $88.4 \%$, respectively). There was no significant difference between the three different dose groups.

As the dose-related correlation between serum gastrin concentrations and gastric acid suppression has been observed, serum gastrin concentration could be used as a surrogate marker for the effectiveness of gastric acid suppression by 
PPI. ${ }^{28}$ Serum gastrin concentrations were also assessed in this study. After oral administration of YYD601 or 40-mg esomeprazole, both mean intragastric $\mathrm{pH}$ during the 24-hour period and percent change of serum gastrin concentrations were significantly elevated in the subjects across the groups, compared to the values determined at baseline. Accordingly, the correlation between serum gastrin elevation and gastric acid suppression was observed in our study.

The present study has several limitations. First, only healthy adult male subjects were enrolled in the study to exclude any factors that may affect the pharmacokinetics and pharmacodynamics. Those who had positive test results for ${ }^{13} \mathrm{C}$ urea breath test were also excluded in this study, in consideration of the study results by Gillen et al and Verdú et al that reported a greater suppression of acid secretion during omeprazole treatment in Helicobacter pylori infection. ${ }^{29,30}$ Furthermore, patients with acid-related disorders may not exhibit the same pharmacodynamic and therapeutic effect as those in healthy subjects. Accordingly, further studies in patients with acid-related disorders might be needed to evaluate the acid inhibitory effect and clinical efficacy, in terms of symptom control or rate of healing of YYD601. Second, the number of the subjects enrolled in the study was relatively small because this study was designed to explore and describe esomeprazole pharmacokinetics and pharmacodynamics after oral administration of YYD601.

YYD601, a once-daily esomeprazole dual DR, $30 \mathrm{mg}, 40 \mathrm{mg}$, or $60 \mathrm{mg}$ for 5 days was well tolerated in healthy adult volunteers enrolled in this study. The overall incidence of AEs was low. Although all 11 AEs in this study occurred following administration of YYD601, no AE was severe in intensity and clinically significant. Accordingly, it is unlikely that it could be an issue after prolonged administration of YYD601, compared to the conventional formulation.

\section{Conclusions}

In this study, YYD601, using DDR formulation technology, showed two distinct peaks with prolonged mean residence time. YYD601, even at lower dose, showed the comparable increase in mean percentage of time with intragastric $\mathrm{pH}>4$ for 24-hour and during night-time, to the conventional esomeprazole. The acid inhibitory effect and clinical efficacy in patients with acid-related disorders might be different from those in this study conducted in the relatively small number of healthy subjects. Accordingly, the results from our study provide a reliable basis to proceed with studies in patients with acid-related disorders. Even though the results from that study show no difference between two formulations, a wider variety of choices could be provided in clinical settings by YYD601. Single and multiple oral dosing of YYD601 up to $60 \mathrm{mg}$ were safe and well-tolerated throughout the study.

\section{Abbreviations}

GERD, gastroesophageal reflux disease; PPI, proton pump inhibitor; NAB, nocturnal acid breakthrough; DR, delayedrelease; DDR, dual delayed-release; KNUH, Kyungpook National University Hospital; LC, liquid chromatography; MS, mass spectrometer; $C_{\max }$, maximum plasma concentration; $T_{\max }$, time to reach $C_{\max }$; $\mathrm{AUC}_{\text {last }}$, area under the plasma concentration-time curve (AUC) to the last measurable time; $\mathrm{AUC}_{\mathrm{inf}}, \mathrm{AUC}$ to infinity; $\mathrm{C}_{\mathrm{max}, \mathrm{ss}}, \mathrm{C}_{\max }$ during a dosing interval $(\tau)$ at steady state; $\mathrm{T}_{\mathrm{max}, \mathrm{ss}}$, the time to reach $\mathrm{C}_{\mathrm{max}, \mathrm{ss}} ; \mathrm{AUC}_{\tau, \mathrm{ss}}, \mathrm{AUC}$ after repeated dosing at steady state; $\mathrm{t}_{1 / 2}$, elimination half-life; AE, adverse event; TEAE, treatment-emergent AE; GMR, geometric mean ratio; CIs, confidence intervals.

\section{Data Sharing Statement}

We, the authors, intend to share individual de-identified participant data. However, there must be a limit on our data sharing, because this study was sponsored by a pharmaceutical company. Young-Ran Yoon should be contacted for the sharing of the data.

\section{Acknowledgments}

The authors are grateful to all study participants and volunteer subjects. This study was sponsored by YooYoung Pharm. Co. Ltd., Jincheon, Chungcheongbuk-do, Korea, and was supported by the grants from Korea Health Technology R\&D Project through the Korea Health Industry Development Institute (KHIDI), funded by the Ministry of Health \& Welfare, Republic of Korea (HI14C2750, HI19C0790). 


\section{Disclosure}

Kyunghee Cho is an employee of Biocore Co. Ltd. The authors report no conflicts of interest regarding this work or the content of this article.

\section{References}

1. El-Serag HB, Sweet S, Winchester CC, Dent J. Update on the epidemiology of gastro-oesophageal reflux disease: a systematic review. Gut. 2014;63 (6):871-880. doi:10.1136/gutjnl-2012-304269

2. Savarino V, Marabotto E, Zentilin P, Demarzo MG, de Bortoli N, Savarino E. Pharmacological management of gastro-esophageal reflux disease: an update of the state-of-the-art. Drug Des Devel Ther. 2021;15:1609-1621. doi:10.2147/DDDT.S306371

3. Bell NJ, Burget D, Howden CW, Wilkinson J, Hunt RH. Appropriate acid suppression for the management of gastro-oesophageal reflux disease. Digestion. 1992;51(Suppl 1):59-67. doi:10.1159/000200917

4. Hunt RH. Importance of pH control in the management of GERD. Arch Intern Med. 1999;159(7):649-657. doi:10.1001/archinte.159.7.649

5. Röhss K, Lind T, Wilder-Smith C. Esomeprazole $40 \mathrm{mg}$ provides more effective intragastric acid control than lansoprazole $30 \mathrm{mg}$, omeprazole $20 \mathrm{mg}$, pantoprazole $40 \mathrm{mg}$ and rabeprazole $20 \mathrm{mg}$ in patients with gastro-oesophageal reflux symptoms. Eur J Clin Pharmacol. 2004;60 (8):531-539. doi:10.1007/s00228-004-0804-6

6. Sachs G, Shin JM, Hunt R. Novel approaches to inhibition of gastric acid secretion. Curr Gastroenterol Rep. 2010;12(6):437-447. doi:10.1007/ s11894-010-0149-5

7. Sachs G, Shin JM, Howden CW. Review article: the clinical Pharmacology of proton pump inhibitors. Aliment Pharmacol Ther. 2006;23 Suppl 2 (s2):2-8. doi:10.1111/j.1365-2036.2006.02943.x

8. Peghini PL, Katz PO, Bracy NA, Castell DO. Nocturnal recovery of gastric acid secretion with twice-daily dosing of proton pump inhibitors. Am J Gastroenterol. 1998;93(5):763-767. doi:10.1111/j.1572-0241.1998.221_a.x

9. Metz DC, Vakily M, Dixit T, Mulford D. Review article: dual delayed release formulation of dexlansoprazole MR, a novel approach to overcome the limitation of conventional single release proton pump inhibitor therapy. Aliment Pharmacol Ther. 2009;29(9):928-937. doi:10.1111/j.13652036.2009.03984.x

10. McKeage K, Blick SK, Croxtall JD, Lyseng-Williamson KA, Keating GM. Esomeprazole: a review of its use in the management of gastric acid-related diseases in adults. Drugs. 2008;68(11):1571-1607. doi:10.2165/00003495-200868110-00009

11. Miner JP, Katz PO, Chen Y, Sostek M. Gastric acid control with esomeprazole, lansoprazole, omeprazole, pantoprazole, and rabeprazole: a five-way crossover study. Am J Gastroenterol. 2003;98(12):2616-2620. doi:10.1111/j.1572-0241.2003.08783.x

12. Wilder-Smith CH, Röhss K, Nilsson-Pieschl C, Junghard O, Nyman L. Esomeprazole $40 \mathrm{mg}$ provides improved intragastric acid control as compared with lansoprazole $30 \mathrm{mg}$ and rabeprazole $20 \mathrm{mg}$ in healthy volunteers. Digestion. 2003;68(4):184-188. doi:10.1159/000075697

13. Lee RD, Mulford D, Wu J, Atkinson SN. The effect of time-of-day dosing on the pharmacokinetics and pharmacodynamics of dexlansoprazole MR: evidence for dosing flexibility with a dual delayed release proton pump inhibitor. Aliment Pharmacol Ther. 2010;31(9):1001-1011. doi:10.1111/j.1365-2036.2010.04272.x

14. Nexium (AstraZeneca Pharmaceuticals LP). Prescribing Information. Available from: https://www.accessdata.fda.gov/drugsatfda_docs/label/2014/ 022101s014021957s017021153s050lbl.pdf. Accessed November 02, 2021.

15. Kim D, Park MS, Yoo BW, Hong T, Park SJ, Kim CO. The safety, pharmacodynamics, and pharmacokinetics of immediate-release formulation containing esomeprazole $20 \mathrm{mg} /$ sodium bicarbonate $800 \mathrm{mg}$ in healthy adult male. Drug Des Develop Ther. 2019;13:3151-3159. doi:10.2147/ DDDT.S212491

16. Wiesner A, Zwolińska-Wcisło M, Paśko P. Effect of food and dosing regimen on safety and efficacy of proton pump inhibitors therapy- a literature review. Int J Environ Res Public Health. 2021;18(7):3527. doi:10.3390/ijerph18073527

17. Liu -Z-Z, Ren Q, Zhou Y-N, Yang H-M. Bioequivalence of two esomeprazole magnesium enteric-coated formulations in healthy Chinese subjects. World J Clin Cases. 2020;8(22):5518-5528. doi:10.12998/wjcc.v8.i22.5518

18. Bergstrand R, Grind M, Nyberg G, Olofsson B. Decreased oral bioavailability of lansoprazole in healthy volunteers when given with a standardized breakfast. Clin Drug Investig. 1995;9(2):67-71. doi:10.2165/00044011-199509020-00002

19. U.S. Food and Drug Administration. Guidance for industry: Food-Effect Bioavailability and Fed Bioequivalence Studies. https://www.fda.gov/ media/70945/download. Accessed February 28, 2022.

20. Mogili R, Kanala K, Bannoth CK, Chandu BR, Challa BR. Quantification of esomeprazole in human plasma by liquid chromatography tandem mass spectrometry and its application to bioequivalence study. Der Pharm Lett. 2011;3(5):138-145.

21. Shin JS, Lee JY, Cho KH, et al. The pharmacokinetics, pharmacodynamics and safety of oral doses of ilaprazole 10, 20 and $40 \mathrm{mg}$ and esomeprazole $40 \mathrm{mg}$ in healthy subjects: a randomized, open-label crossover study. Aliment Pharmacol Ther. 2014;40(5):548-561. doi:10.1111/ apt. 12860

22. Hunt RH, Armstrong D, Yaghoobi M, James C. The pharmacodynamics and pharmacokinetics of S-tenatoprazole-Na $30 \mathrm{mg}, 60 \mathrm{mg}$ and $90 \mathrm{mg}$ vs. esomeprazole $40 \mathrm{mg}$ in healthy male subjects. Aliment Pharmacol Ther. 2010;31(6):648-657. doi:10.1111/j.1365-2036.2009.04219.x

23. Hassan-Alin M, Andersson T, Bredberg E, Röhss K. Pharmacokinetics of esomeprazole after oral and intravenous administration of single and repeated doses to healthy subjects. Eur J Clin Pharmacol. 2000;56(9-10):665-670. doi:10.1007/s002280000206

24. Lind T, Rydberg L, Kylebãck A, et al. Esomeprazole provides improved acid control vs. omeprazole in patients with symptoms of gastro-oesophageal reflux disease. Aliment Pharmacol Ther. 2000;14(7):861-867. doi:10.1046/j.1365-2036.2000.00813.x

25. Shin JM, Sachs G. Pharmacology of proton pump inhibitors. Curr Gastroenterol Rep. 2008;10(6):528-534. doi:10.1007/s11894-008-0098-4

26. Johnson DA, Katz PO. Nocturnal gastroesophageal reflux disease: issues, implications, and management strategies. Rev Gastroenterol Disord. 2008;8(2):98-108.

27. Gardner JD, Perdomo C, Sloan S, et al. Integrated acidity and rabeprazole pharmacology. Aliment Pharmacol Ther. 2002;16(3):455-464. doi:10.1046/j.1365-2036.2002.01158.x

28. Robinson M. Review article: current perspectives on hypergastrinaemia and enterochromaffin-like-cell hyperplasia. Aliment Pharmacol Ther. 1999;13(Suppl 5):5-10. doi:10.1046/j.1365-2036.1999.00033.x 
29. Gillen D, Wirz AA, Neithercut WD, Ardill JE, McColl KE. Helicobacter pylori infection potentiates the inhibition of gastric acid secretion by omeprazole. Gut. 1999;44(4):468-475. doi:10.1136/gut.44.4.468

30. Verdú EF, Armstrong D, Fraser R, et al. Effect of Helicobacter pylori status on intragastric pH during treatment with omeprazole. Gut. 1995;36 (4):539-543. doi:10.1136/gut.36.4.539

\section{Publish your work in this journal}

Drug Design, Development and Therapy is an international, peer-reviewed open-access journal that spans the spectrum of drug design and development through to clinical applications. Clinical outcomes, patient safety, and programs for the development and effective, safe, and sustained use of medicines are a feature of the journal, which has also been accepted for indexing on PubMed Central. The manuscript management system is completely online and includes a very quick and fair peer-review system, which is all easy to use. Visit http://www.dovepress.com/testimonials.php to read real quotes from published authors.

Submit your manuscript here: https://www.dovepress.com/drug-design-development-and-therapy-journal 